\title{
La original expresión poética de Silvina Ocampo
}

$\mathrm{S}^{\text {ILvina Ocampo nació en Buenos Aires y, como su hermana Vic- }}$ $\$$ toria, ha viajado por Francia, país venerado al que debe sus primeros gustos literarios sin ser por ello menos argentina. Su obra en verso consta de Enumeración de la patria y otros poemas (1942), merecedor del premio municipal de literatura para 1942; Espacios métricos (1945) y Poemas de amor desesperado (1949). En prosa ha escrito un libro inicial de recuerdos de infancia titulado Viaje olvidado (1937), una novela policíaca en colaboración con Adolfo Bioy Casares Los que aman, odian (1946) y una colección de cuentos Autobiografía de Irene (1948). También es editora, con Jorge Luis Borges y Adolfo Bioy Casares, de una Antología de la literatura fantástica (1941 y de una Antologia poética argentina (1941).

Enumeración de la patria significó un acontecimiento en la poesía argentina. Mereció entusiastas elogios de críticos que compararon a su autora con poetas consagrados, o que por lo menos mencionaban su nombre, con los de Berceo, Walt Whitman, Browning, Ben Johnson, Lugones y Guillén, ${ }^{1}$ y también críticas acerbas de quienes vieron en él graves defectos, o supusieron que el gran éxito de Silvina, se debía a sus vínculos con Sur. En todo caso, hay que reconocer que este primer volumen tiene abundantes aciertos y que es una manifestación original de la Argentina de hoy.

Entre los poemas de este primer volumen nos interesan, sobre todo, los primeros. Son en su mayoría de amor y de pasión por la patria; hecho que, junto con su originalidad de la que hablaremos en seguida, los salva y redime de la posible monotonia en que una poesía descriptiva de esta índole pudiera fácilmente caer. La autora 
"enumera" en voluntario desorden la belleza provinciana, los humildes y honrados pueblecitos, las florecientes ciudades de San Isidro del Plata, de Buenos Aires y Córdoba. Este procedimiento descriptivo, introducido en la poesía moderna por Walt Whitman $y$ adoptado por algunos poetas de lengua española, entre los cuales se cuentan Lugones, Herrera y Reissig, Ramón López Velarde y Neruda, es también el que sigue Silvina Ocampo, quien alaba los atributos patrios, con el mismo espíritu de veneración con que Lugones se expresa en las Odas seculares; sobre todo, en poemas como "Al Plata", "A los ganados y las mieses", y "A Buenos Aires". Estos dos poetas difieren, sin embargo, por el hecho de que Silvina, fiel al título de su libro, es esencialmente enumerativa, mientras que Lugones es más descriptivo de las escenas y el sentido de la vida. A Silvina la emociona el recuerdo del paisaje fragmentado y mínimo, de cuya totalidad surge el significado vital del país; a Lugones le emocionan, además, los acontecimientos, por lo que significan simbólicamente en la evolución de la patria; de ahí que los subraye. Veamos algún ejemplo:

Silvina: Oh, desmedido territorio nuestro

Violentísimo y párvulo. Te muestro.

En un infiel espejo...

Tienes plantas y pájaros salvajes,

Somnolientas mujeres en corpiño

Trenzándose los dedos. Quietas balsas

para cruzar los ríos. Cangrejales

devoradores de hombres $y$ animales,

montes de hijas negras y descalzas

cruzando tus desiertos y estaciones.

Tienes provincias y gobernaciones,

poblaciones vacías y distancias

con nombres melancólicọs de estancias... (pág, 9) 2

Lugones: Un verde matinal lustra los campos, donde el otoño, en languidez dichosa, con dotado de soles que se atardan va dilatando madureces blondas.

A través de la pampa, un río, turbio de fertilidad, rueda silenciosa su agua que tiene por modesta fuente la urna de tierra de la tribu autóctona... 
Como la negra fiel de las familias, obesa y atareada ríe la olla bajo el sabroso mecedor de higuera los dientes blancos de la mazamorra. 3

Al procedimiento enumerativo de Silvina Ocampo se le ha llamado elogiosamente: "ordenación venturosa", 4 "firme unidad de jerarquia poética", 5 "dominio sin énfasis del verso", "sabor uniforme de la masa verbal". ${ }^{7}$ No era ésta la opinión de Ana María Chouhy Aguirse, directora de Verde memoria, la cual vió en el libro elementos que "se acumulan en desorden", y en la forma, una "simplicidad artificiosa". ${ }^{8}$ Esta crítica es quizás demasiado severa. Lo mismo se había dicho del poema descriptivo "La suave patria", de Ramón López Velarde, con el cual mucho tiene de común Silvina Ocampo, por haber rehuído sistemáticamente el lugar común. A nuestro parecer se encuentra más variedad, quizás no de tema pero sí de tono, en López Velarde, entregado sucesivamente al prosaísmo irónico y a la pasión intensa de su amor patrio. En Silvina Ocampo la ironía es menos evidente, por ser más sutil, y la excesiva constancia de pasión neutraliza un tanto el contraste que encierran los endecasílabos. He aquí un fragmento sobre Buenos Aires:

Anterior a tus casas, Dios te amaba.

Solo, imitando al sol, te contemplaba.

Hombres, después, te amaron: desde un barco

el navegante, el indio con el arco,

el señor que está incómodo en su arcano

retrato con el lente en una mano,

el que murió sin un retrato y triste

de no dejar un rostro que subsiste. (pág. 15.)

Esta ironía que se atiene al aspecto exterior de las cosas, más que al sentido, tiene un carácter algo francés, como en ese imperceptible gesto de elegancia aristocrática y decadente del "señor del lente"; contrasta con la franca ironía romántica aplicada a sí mismo, de Ramón López Velarde, como se podrá juzgar por este fragmento del "Proemio" a "La suave patria": 

Yo que sólo canté de la exquisita partitura del intimo decoro, alzo la voz a la mitad del foro a la manera del tenor que imita la gutural modulación del bajo, para cortar a la epopeya un gajo. 9

Los nombres exóticos que abundan en el poema de Silvina lo recargan por la erudita fantasía con que los usa la autora. Por ello dijo la severa Ana María Chouhy Aguirre que Enumeración de la patria le recordaba "aquella terrible "Fiesta popular de Ultratumba'. de Herrera y Reissig" ${ }^{10}$ que, de paso sea dicho, es uno de los maestros de López Velarde.

Un elemento que caracteriza la primera poesía de Silvina Ocampo es, como indica Jorge Luis Borges, el de la "casi inhumana, casi estoica impersonalidad" 11 "que no impide, sin embargo, que intercale la autora su nombre entre los endecasilabos; lo cual, más que un gesto de individualismo romántico, es un ademán de objetividad poética al estilo oriental. La autora se ve objetivamente contra un paisaje. El poeta Borges indica que lo mismo hacen los persas y algunos occidentales; entre ellos, Browning, Ben Johnson y Walt Whitman. Veamos, una vez más, los versos de Silvina:

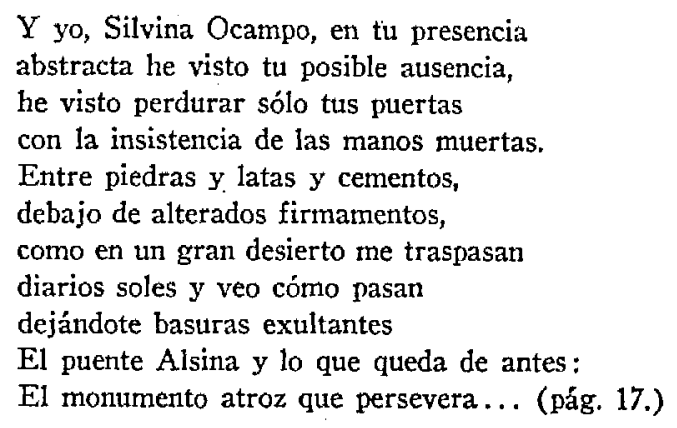

Por los versos que acabamos de citar, como por muchos otros, pasa el recuerdo de Neruda, en la predilección por detenerse a menudo en lo repulsivo, lo cual contrasta con las bellezas expuestas a to largo del poema. Abundan "sombras y basuras", "venenos predilectos", "perfumes de tumbergias pegajosas", "latas y cementos", "amputados árboles sombríos", "un enfermo", "una niña que escupa en las ventanas". 
Una cualidad de los pareados de Silvina Ocampo, tan perfectos y concluyentes, es la de estar dotados de extraordinaria elasticidad, debido al sentido rítmico de la poetisa que se resiste a concluir la frase poética al final de cada dístico haciéndonos pasar de verso a verso con el impulso del sonido y de la idea, sin que nos sea posible hacer pausas que no quiso otorgarnos. $Y$ por mucho que se opongan Verlaine y Silvina, fuerza es reconocer que el procedimiento musical del simbolismo francés del autor de Romances sans paroles, o por lo menos de la corriente que deriva de él, le da una calidad especial de fluidez a esta poesía hecha de metáforas paradojales, de contrastes, de aserciones inesperadas; véanse las citas anteriores. Maneja además la rima con excepcional soltura, pese al uso frecuente del verbo en tercera persona para cumplir con sus exigencias; pero aun en estos casos, tiene tal aire de desenvoltura que no nos molesta este subterfugio. El juego fino de aliteraciones, así como la aproximación de elementos fónicos contribuyen a la fluidez del verso:

\author{
Sonoros de relinchos quebradizos (pág. 9.) \\ Tienes plantas y pájaros salvajes (pág. 10). \\ Tienes provincias y gobernaciones, \\ Pablaciones vacías... (pág. 10.) \\ PERfumes de tumbergIAS PEgaJOSAS (pág. 12). \\ Las olas y las algas y las alas (pág. 81). \\ He copiado y después he transformado \\ los arcanos paisajes y las manos \\ los veranos, los ANGEles hermanos, \\ He venerado en sombras el rosado \\ Con tintas puedo iluminar las quintas \\ extintas, las sirenas ya distintas (pág. 119).
}

Más que la adjetivación, siempre original, nos gana por lo versátil de su pensamiento, atento a extrañas pero eficaces afinidades:

Tứs noches y caminos despoblados

y con rebaiio de ojos constelados (pág. 9.)

Tienes plantas perversas $y$ sumisas, con todos los venenos predilectos de muertes repentinas y precisas (pág. 11.) cuando los vendedores ambulantes cuentar sus mercancías como amantes. (pág. 19.) 
hasta el río Luján cruzaré al Alba Nueva como en el Paraíso la deslumbrada Eva. (pág. 30.)

y lenta la trenzada mecedora evoca una pacífica señora. (pág. 34.)

Pálido San Jerónimo es tu patrón; lo adoran atareadas señoras y ávidas lo decoran (pág. 46.)

$\mathrm{Tu}$ arborado vestido tiene como los santos

flores de lentejuelas y algunos desencantos (pág. 49.)

Todo es mentira y todo es cierto ahora;

la bofetada, el livido estileto

el principio falaz de algún soneto (pág. 133.)

La predilección por el uso de la preposición con, usada en inglés, cuando en español se diría de, es otra originalidad, no carente de cierto exotismo, cuya intención parece ser la de producir una impresión de abundancia:

Grandes patios con muchas ventolinas (pág. 10.)

En múltiples espejos con lombrices

Vió tu río pintado con barnices (pág. 16.)

paisanas

atentas, con saludos apacibles (pág. 34)

[la procesión] lleva santos con ojos oscuros (pág. 45)

tus batas con cintas delirantes (pág. 67.)

Este libro, original y extraño, de Silvina Ocampo, sobre un tema no enteramente nuevo, pone en evidencia una fantasía poco común, sazonada por elementos eruditos y exóticos, de gusto francés unas veces, inglés otras, en su conjunto cosmopolita, que indica, por la pulcritud y el uso especial de la palabra, por la necesidad de rima y de ritmo, así como por la tendencia al verso regular, un sentido menos ultramodernista que clásico, que confirman sus siguientes libros de versos.

Espacios métricos es un libro de fantasía ultramoderna y de forma absolutamente tradicional, integrado por sonetos, cuartetos y pareados, aunque de vez en cuando también escribe unas cuantas poesías, sin rima. El residuo de retórica, que le hizo decir a la autora de Los dias perdidos que su primer libro estaba "recargado de literatura", ${ }^{12}$ ya no se encuentra sino en alguna de las composiciones del principio. En su lugar aparece un verso del cual ha dicho Ezequiel Martinez Estrada que es de "articulaciones apretadas, todo 
lleno, siempre más corto que la longitud inicial de lo que contiene ..."13 En estas formas compactas de acento clásico vierte Silvina Ocampo un mundo de fantasías, de sueños originados en visiones de horror, de símbolos enigmáticos, de trascendencias extrañas y de alucinaciones que nos huyen o que se transforman bajo el poder de felices asociaciones. La rima y la consonancia les dan a sus fantasías el espejismo de encerrar verdades definitivas, soluciones, conclusiones, $\mathrm{y}$ a sus experiencias o acontecimientos imaginados la naturalidad de lo cotidiano.

El tema que nos parece más constante, el mismo siempre pero multiforme, es el del mecanismo interno de la conciencia con sus actividades y deducciones mediatas que Silvina Ocampo quiere sorprender en pleno funcionamiento. Con su manera directa, sencilla, casi despreocupada se acerca a la meta soñada por los superrealistas y dadaístas: el aprisionamiento de la verdad íntima del ser humano.

Como los surrealistas, emplea un lenguaje familiar; pero se diferencia de ellos por su mayor minuciosidad detallista que produce una falsa primera impresión de claridad que en seguida se llena de sombras para ir oscureciendo una expresión que habiamos creído penetrar.

La realidad objetiva es el pretexto de otra realidad mucho más viva y actual, mucho más verdad que aquélla: la realidad de la imaginación que juega con los acontecimientos, los recuerdos, los objetos, y que nos los devuelve recreados a la luz de deducciones pseudopsicológicas. Con la imaginación se proyecta hacia hechos del futuro cuya realidad conoce ya con seguridad y exactitud, pues este futuro inventado ha sido construido con el conocimiento profundo, mediato e intuitivo del propio ser. Vidente porque conoce a fondo. sus reacciones y por eso su pasado, Silvina Ocampo conoce toda su realidad, o mejor dicho todas sus posibles realidades, y así el presente pierde su valor y su prestigio ante cualquier momento de un futuro inventado que puede usurparle el lugar de actualidad. De ahí que el miedo imaginado, mucho más escalofriante que el miedo procedente de una causa concreta, aumentado por el conocimiento de todos los sentimientos de terror conocidos en diferentes circunstancias, adquiera un carácter angustiosamente real. Paradójicamente Silvina lo expresa con austera objetividad: 
Por qué lo temes si no existe sino en tus stueños ese oscuro instante de esta mansión antigua, trepidante, donde un fantasma anónimo persiste. (pág. 110.) 14

Su actitud frente a la realidad es uno de los elementos más originales de sus versos. Véamos, pues, más de cerca este aspecto de su poesía.

En "Autobiografía de Irene" (págs. 81-92), que tiene una versión, en prosa publicada en Sur el año precedente, nos da la clave de su concepción poético-psicológica:

Con transparencias trémulas de velo el porvenir me revelaba nombres, rostros antes de haberlos conocido, sendas antes de haberlas recorrido. Yo veía las cosas transfortnadas por el tiempo anhelante, reformadas.

Podia tecordar sólo el futuro:

cómo iba a ser mi casa y no cómo era, los niños todos ya con rostros de hombres, marchitos los botones de las rosas, florecida la ausente enredadera. Muertas podía ver a las personas que estaban por morirse

Yo sólo recordaba el porvenir... (pág. 88.)

Curioso este trabajo subterráneo de la imaginación. En la "Autobiografía de Irene" en prosa, pequeña pseudo-autobiografía que figura al final de un libro que lleva el mismo título, leemos un extraño relato de Irene que nos cuenta cómo ya antes de la muerte del padre, ha preparado las ropas de luto, le ha llorado y ha ido a depositarle flores en el cementerio, de modo que cuando el hecho real acontece, a ella no le afecta ya $y$ vive en el recuerdo de aquella otra muerte imaginada. Algo parecido sucede con Gabriel, el muchacho a quien promete recordar toda la vida y a quien ya ha relegado a un pasado entre el cual y ella se interponen todos los rostros que ha de conocer en el futuro. ${ }^{15}$ Este motivo lo volvemos a encontrar en sus versos. ${ }^{16}$ 
Este futuro, una vez pensado, tiene un sello de predestinación, del que ya no puede escapar. Irene, o Silvina, habla:

\author{
Trataba a veces de modificar \\ las partes tristes del futuro en vano: \\ no conseguía lluvias del verano \\ y perdían mis padres las cosechas, \\ no lograba tampoco hacerle amar \\ a mi prima aquel joven que la amaba. (pág. 89.) \\ No tengo que pensar, yo me decía \\ con tanta rapidez, pero eran flechas \\ que me hacian sangrar mis pensamientos \\ como a San Sebastián en su agonía... (pág. 89.)
}

El hecho mismo de pensar los acontecimientos los fija, pues, para siempre en ese recuerdo que pertenece al futuro. Por eso piensa Irene que piensa con demasiada precipitación saqueando y malcreando el porvenir. Pero ¿qué hacer si son relámpagos las ideas que cruzan su cerebro convirtiéndose así en seguro azar, antes de que pueda rechazarlas? La imaginación, más poderosa que la voluntad, se impone con su terrible dominio creando acontecimientos inesperados hasta para el poeta mismo.

Esta virtud o desgracia de proyectarse tan fácilmente hacia el futuro de las cosas es justamente la mayor traba para el goce del presente, pues éste pierde todo su poder ante el "recuerdo mágico". Hay, sin embargo, una compensación:

Ahora aunque esté sola no te pierdo

Un recuerdo de amor es infinito... (pág. 92.)

Lo mismo deducimos del soneto "La eternidad" del que hay dos versiones que corresponden a dos momentos del sentimiento de la eternidad. Al mismo tiempo se perfila una faceta nueva: la mutabilidad del presente, menos nuestro que el recuerdo o el porvenir que tiene ese carácter fijo que hemos anotado:

Cuando en el mundo oscuró te alejabas

en el estereoscopio me dejabas:

allá para mí sola restituía

la inmóvil dicha en la fotografía.

[línea en blanco] 
Como por galerías de bondad yo penetraba ese apacible mundo alcanzando ya un tiempo más profundo prenatal de silencio y gravedad. Ah, cómo hería el ave en los caminos y marchitaba rosas en los pinos $y$ te cambiaba el alma alegremente con su constancia infiel la realidad. En el estereoscopio claramente se formaba tu dulce eternidad. (pág. 147.)

Lo más eterno y constante del presente no es otra cosa que su mutabilidad. La idea filosófica que expresa el soneto arriba citado, se encuentra en varias composiciones; pero sobre todo en "Fidelidad" (pág. 29): la ausencia del amado que está a su lado no es esa ausencia corrientemente llamada alejamiento espiritual sino la ausencia de cada gesto, de cada sentimiento y de cada palabra dicha que no pueden repetirse ya más porque cada momento muere al nacer el siguiente:

El verdadero cambio, el más sutil, te habita...
Me abrumarás de ausencias para no repetir
ademanes, palabras, palabras que he invocado.
Idéntico a ti mismo, no quieres acudir. (pág. 30.)

Todo lo que hay de paradojal en la poesía de Silvina Ocampo tiene un aspecto metafísico, $\mathrm{y}$ así junto con la huida de todas las. cosas reales viene el regreso de todas las cosas abstractas. En "El crimen" nos dice con un tono que todavía nos recuerda al Neruda de Residencia en la tierra:

Este mismo silencio infernalmente antiguo, esta postura que me da terror oscuro entre los muebles, ah, los reconozco irremisiblemente (pág. 39.)

A propósito del mundo poético de Silvina Ocampo, escribe Ezequiel Martínez Estrada: 
[EI pasado de Silvina] en actualidad es un pasado que se comunica con cualquiera de las formas absurdas de lo que este presente hace imposible. Sus astuntos y sus figuras pertenecen a un mundo que tiene con el nuestro necesarias analogías y simetrías, también con sus seres $y$ sus cosas análogas, hasta con su correlativa historia universal, y que es, sin embargo, el mismo. ${ }^{17}$

La entrega a realidades abstractas no se alcanza impunemente: se paga con la vida, es decir, con la renuncia completa al presente. De ahí también que esta poesía traiga consigo una "reminiscencia de paraíso perdido, de infierno en sueños transitado", como dice cl poeta Martínez Estrada. Así y todo, Silvina se entrega a este sueño continuo que revela "el valor de nuestra alma y la consuela / con lo que nos hará después sufrir." (Pág. 133).

En función de esta original actitud frente a la realidad, se dibuja el concepto de la muerte en completo acuerdo con el mundo paradojal (aunque no psicológicamente irreal, i cuántos no se habrắn reconocido en él!) de Silvina Ocampo. El "León cautivo en una medalla", que lleva un dístico de Víctor Hugo ("Et j'ai pris, ô lions, dans cette intimité, / L'habitude du gouffre et de l'éternité"), ha soñado su muerte, y la prisión cierta, en la medalla, símbolo quizás de este porvenir hecho cierto azar, que gobierna la poesía de Espacios métricos:

Pretéritos veranos me visitan

y por eso la sombra me ilumina

y trémulos mis párpados se entornan

como si respiraran una rosa

si una tosa existiera para mi.

El clamor de mi voz, como el clarín

en hiperbólicas y oscuras grutas,

en mi recuerdo mágico, perdura.

Conocí antiguos mundos y estoy preso

en los jardines tristes, en la piedra (pág. 17)

Y más lejos, al final ya, leemos:

En un sueño me vi en una medalla y desde entonces temo estar en su ámbito.

¡Qué pesado es el sueño ahora y cierto!

Me demoro en la fuente de memorias como los hombres vanos en las rosas: (pág. 21.) 
El libro todo, más particularmente la "parte de los sonetos", es de perfección enteramente clásica. No es el hecho de expresarse en sonetos lo que la lleva hacia este clasicismo sui generis: también se expresaban en sonetos los modernistas y en general los poetas de todos los tiempos, a excepción de la mayoría de los románticos y de los ultramodernistas. En el tratamiento del verso, condensado, conciso, dominado por la forma que organiza el caos de la imaginación y de la fantasía, grabando como en una medalla el fluir paradojal del pensamiento, recortándole un límite, lo cual produce la impresión de las cosas perfectas y acabadas, de los pensamientos definitivos. Pero no es eso todo. Aun cuando Silvina Ocampo nos habla de sí misma, sea directamente, sea a través de Irene, ese personaje excepcional de sus cuentos y sus versos, lo hace con un sentido objetivo, desindividualizado; las confusas experiencias psicológicas. del ser humano se encuentran a lo largo de estos versos, a través de todos los ."yos". Encontramos además en esta poetisa un gusto por la descripción de las formas exteriores, que aparece aquí y allá y que dota al poema de una limpidez clásica:

-Esa trémula rosa que en tu pecho
me parece de mármol, ese helecho
de tu pelo trenzado, atardecido,
yo los he como a ti reconocido.
-Esa forma redonda de tu cuello
y en tu boca el asombro como un sello
pidiendo a mis palabras un secreto,
ese consuelo efímero, indiscreto,
de tus abiertos ojos, ¿los visito
por vez primera?... (pág. 49.)

Así comienza la poesia titulada "Primer encuentro". Contribuye a evocar el ambiente clásico; el uso frecuente, entre apropiado y fantástico de la antigüedad griega, de la Edad Media, de la Biblia y de los grandes poetas clásicos. ${ }^{18}$ Junto con el vocabulario corriente y prosaico, como "repugnante", "prostitutas", "consabidas", "abyecto", encontramos este otro, elegante y culto, que usaban los clási$\cos$ y los modernistas: "adamantino", "conturba", "candorosa", "bucólicas", "grávido", "asfodelo", "salvia" (las dos últimas palabras son de plantas medicinales). $Y$ frente al clasicismo de forma, severo y estricto, encontramos la indecisión, la duda, la ambigüe- 
dad de la emoción inasible, tan características de los ultramodernistas; sobre todo, de Pablo Neruda, a tientas en busca de la eternidad a través de la constante fluctuación de todas las cosas. ${ }^{19}$ Por eso también hay en Espacios métricos versiones de la misma emoción o del mismo pensamiento, aprisionados en los clásicos y rigurosos versos. En "La abandonada", por ejemplo, leemos en la primerá versión:

Ella sola se irá como en un sueño

como en un sueño donde brilla el frío. (pág. 35.)

En la segunda versión dice:

Por eso estoy acá como en un suefio

como en un sueño largo que no es mío. (pág. 37.)

No se trata de una contradicción sino de imprecisas emociones que se complementan a través de enfoques diferentes. La palabra escrita reduce la multiforme vaguedad de la emoción a una sola dimensión. Es aquello que decía Stéphane Mallarmé, de que el más hermoso poema es el de la página blanca, el que aún no se ha escrito. Cada emoción es insustituíble, dirán otros poetas refiriéndose a lo mismo. Si es ello cierto, Silvina, ingenua pero conscientemente, nos ta sus "versiones de emociones insustituibles, como lámina de caleidoscopio para la sensibilidad del lector.

A pesar de su temperamento apasionado, impulsivo, Silvina Ocampo se deleita en el mágico poder de las palabras, de las paradojas ${ }^{20}$ y se detiene con fruición intelectual en los efectos de ciertas asociaciones de palabras de belleza intrínseca que condensan mundos de sugerencias afines, para deleite del pensamiento más que del corazón. El verso se vuelve a menudo hermético. El articulista anónimo que reseñó este libro en La Nación el año de su aparición, decía: "Sería menester elevarse a ... Stéphane Mallarmé para encontrar un ejemplo de hermetismo de tan vital influjo." ${ }^{21}$ Hay en efecto un posible acercamiento entre ambos, que reside justamente en ese simbolismo ligeramente parnasiano que vincula al gran poeta francés con el clasicismo. $Y$ es posible que el alto ejemplo de Stéphane Mallarmé haya sido incentivo para quien seguramente le ha leído y gustado, por estar, en cierto modo, tan cerca de su visión compleja de la realidad. 
Poemas de amor desesperado es un libro que diverge de los anteriores, por la orientación. Parece ser hijo de las amarguras hutmanas que han desterrado, por el momento al menos, la paradojal fantasía de antes, para imponerse con toda la fuerza de su angustiosa presencia. Aparte de las "traducciones" que componen la última parte del libro y de algunas composiciones más que continúan la inspiración de antes (ej. "Fantasmas de las glicinas"), aquella casi inhumana impersonalidad de que hablaba el poeta Borges ha desaparecido y en su lugar hay un elemento muy personal e íntimo que matiza casi todos los temas. La misma Silvina se lamenta, en un hermoso soneto de la primera parte, de no ser "tan impersonal como las rosas". A través de una expresión más directa, más seritida, quizás menos original también, subsisten los elementos que mencionábamos antes como característicos de su estilo. ${ }^{22}$ Nos parece éste un libro hermoso que contiene muchas poesías conmovedoras, pero un poco aparte en el conjunto de su producción, o el comienzo de algo nuevo.

Creemos que, en lo mejor de su poesía, Silvina Ocampo ha logrado dar expresión al complicado y sutil mecanismo de la conciencia femenina frente al problema de la realidad, con esa su manera personalísima de plantear y en cierto modo de resolver un problema que ha dejado de ser exclusivamente del dominio de la filosofía para convertirse en angustioso problema vital de los poetas actuales siempre en busca de la eternidad.

Helena Percas, Grinnell College.

\section{NOT A S}

1 Véanse los artículos de Fina García Marruz, "Espacios métricos por Silvina Ocampo", Orígenes, Habana, 1949, irr, núm. 11, 44-45; de Jorge Luis Borges, "Silvina Ocampo, Entmeración de la patria", Sur, Buenos Aires, 1943, XII, núm. 101, 64-67, y de C. M., "Silvina Ocampo: Enumeración de la patria", Paraná, Rosario, Argentina, 1943, in, núm. 4, 173. 
2 Buenos Aires, Sur, 1942.

3 Antología poética, 1941, pp. 94 y 102.

4 C. M., op. cit., p. 172.

5 C. Varela Avellaneda, "Silvina Ocampo: Enumeración de la patria", Sustancia, Tucumán, 1943, IV, 386.

6 Ibid., p. 387.

7 Fina Garcia Marruz, op. cit., p. 43.

8 "Enumeración de la patria, por Silvina Ocampo", Verde memoria, Butenos Aires, 1943, núm. 5, 22.

9 México, Imprenta Universitaria, 1944, j. 5.

10 Loc. cit.

11 Op. cit., p. 65.

12 Loc. cit.

13 "Silvina Ocampo, Espacios métricos", Sur, Buenos Aires, 1946, xv, N* $137,82$.

14 Buenos Aires, Sur, 1945.

15 Sur, Buenos Aires, 1944, xIV, No 117, 12-29.

16 Le dice a Gabriel :

Te conoci mucho antes de encontrarte: ya presentía cómo iba a olvidarte, y traté de esquivar tu encuentro en vano.

Te olvidaba al llevarte de la mano. (pág. 91.)

17 Op. cit., p. 86.

18 En apostilla se encuentran referencias como las siguientes: The Arabian Nights, Burton; "Les lions", Victor Hugo; "A Hymn to Christ", John Donne; "Soneto XXXII", Garcilaso de la Vega; "Etude pour Narcisse", Paul Valéry; "Sui amantes, sine revali", Cicerón; "At a solemn Musick", Milton; "In memoriam", Tennyson.

19 Léase el "Arte poética" o "La melancolía en las familias" de Residencia en la tierra. (Buenos Aires, Losada, 1944, pp. 77 y 199) y se observará esa multiplicidad huidiza de la emoción, o ese "desequilibrio entre la intuición y el sentimiento", como lo llama Amado Alonso.

20 Su espiritu paradojal se hace evidente no sólo en las ideas sino hasta en el barroquismo de la adjetivación: "claridad oscura", "callados ruidos", "constancia infiel". (Pp. 69, 69 y 148, respectivamente.) 
21 "Espacios métricos, Silvina Ocampo", La Nación, Buenos Aires, 30 de diciembre de 1945.

22 Por ejemplo el gusto por la aliteración ("en los labios y libros que admiré") o la asociación ingeniosa ("un infierno privado"), pp. 30 y 100, respectivamente, (Buenos Aires, Editorial Sudamericana, 1949). 